\title{
Notícias sobre uma expedição: Jean Massart e a missão biológica belga ao Brasil, 1922-1923
}

\author{
Notes on an expedition: Jean Massart and the \\ Belgium biological mission to Brazil, 1922-1923
}

\section{Alda Heizer}

Escola Nacional de Botânica TropicalJardim Botânico do Rio de Janeiro Rua Pacheco Leão, 2040. Solar da Imperatriz

22210-030 - Rio de Janeiro - Brasil aldaheizer@jbrj.gov.br
HEIZER, Alda. Notícias sobre uma expedição: Jean Massart e a missão biológica belga ao Brasil, 1922-1923. História, Ciências, Saúde Manguinhos, Rio de Janeiro, v.15, n.3, p.849-864, jul.-set. 2008.

\section{Resumo}

Em 1922, chegou ao litoral brasileiro um grupo de naturalistas viajantes, liderados pelo belga Jean Massart. Registrada em imagens que integram a obra Une mission biologique belge au Brésil 1922-1923, a referida missão teve como objetivo coletar exemplares para o herbário de Bruxelas.

Palavras-chave: naturalistas viajantes; missão científica; imagens; Brasil século XX.

\section{Abstract}

In 1922, a group of traveling naturalists reached the Brazilian coast, led by Jean Massart, a Belgium. The goal of this mission was to collect specimens for the Brussels herbarium, as recorded in images found in Une mission biologique belge au Brésil, 1922-1923.

Keywords: traveling naturalists; scientific mission; images; Brazil; twentieth century. 
O creosoto com que, antes de partir em expedição, eu impregnava minhas bagagens para protegê-las das térmitas e do mofo, percebo ainda seu odor quando entreabro meus cadernos de notas. Quase indiscernível após mais de meio século, esse vestígio, no entanto, torna imediatamente presentes os cerrados e as florestas do Brasil Central, componente indissociável de outros odores, humanos, animais e vegetais, e também de sons e de cores. Por mais fraco que tenha ficado, esse odor, perfume para mim, é a coisa mesma, uma parte sempre real do que vivi.

(Claude Lévi-Strauss, Saudades do Brasil)

$\mathrm{O}$ presente texto aborda aspectos da viagem do biólogo Jean Massart ao Brasil e integra uma pesquisa desenvolvida no Instituto de Pesquisas-Jardim Botânico do Rio de Janeiro sobre iconografia de expedições na primeira metade do século XX, cujo objetivo, entre outros, é analisar os registros dessas viagens, bem como identificar nas fotografias que acompanham o material produzido nesses empreendimentos, o que Lévi-Strauss chamou de uma "sensação de vazio", mais do que de uma presença: "uma falta daquilo que a objetiva é intrinsecamente incapaz de captar" (Lévi-Strauss, 1994, p.9).

Sendo assim, levar ao leitor notícias sobre a viagem de um grupo de naturalistas belgas ao Brasil, no início da segunda década do século XX, sublinhando que o papel do Jardim Botânico do Rio de Janeiro na organização e na definição do percurso realizado pelos integrantes da 'missão' pode ser uma contribuição à história, e à história da botânica em particular.

\section{O Jardim Botânico do Rio de Janeiro e a 'missão'}

O Jardim Botânico do Rio de Janeiro (JBRJ), por meio de seus pesquisadores, tem como uma de suas funções desenvolver trabalhos de campo e, historicamente, manter intercâmbio com instituições brasileiras e estrangeiras.

Durante as primeiras décadas do século XX, a entidade indicou naturalistas e organizou viagens para serem propostas pelo governo brasileiro e por governos de outros países. Uma dessas viagens interessou-me particularmente: a missão biológica belga ao Brasil, realizada entre 1922 e 1923.

Considerada pelos pesquisadores e professores que analisaram os resultados da viagem, sobretudo como uma contribuição ao estudo da biogeografia do Brasil, a 'missão' belga apontou especialmente a relevância dos estudos sobre a Amazônia, dado que, segundo seus membros, a região fora pouco estudada até então. A publicação teria como mérito, segundo seus integrantes, o fato de ter privilegiado o "baixo-Amazonas" ao passo que as outras obras teriam destacado o "alto-Amazonas". A 'missão' foi considerada, ainda, por seus contemporâneos, o prolongamento de um vasto movimento de interesse botânico presente no início do século XIX, com as viagens ao Brasil realizadas pelo também belga Van Houte, em 1834. 


\section{A viagem e o naturalista}

Em meados de 1922, partiu de Anvers, na Bélgica, um grupo de jovens naturalistas, especialistas em botânica e zoologia, alguns deles ligados à Universidade de Bruxelas, e outros, ao Jardim Botânico Léo Errera, da mesma universidade: Jean Massart, professor e diretor do Instituto Botânico Léo Errera da Universidade de Bruxelas (coordenador da viagem); Raymond Bouillenne, doutor em ciências botânicas da Universidade de Liége; os doutores em ciências botânicas Paul Ledoux, Albert Navez e Paul Brien, doutor em ciências zoológicas, os três últimos da Universidade de Bruxelas.

Idealizada pelo médico e biólogo Jean Massart, identificado como "um pioneiro na conservação da natureza na Bélgica" (Massart et al., 1930, p.7), a 'missão', oficialmente, se estendeu por diferentes locais do Brasil e teve como objetivos o estudo da fauna e da flora e o recolhimento de objetos para demonstração nos cursos universitários, bem como de materiais de estudo para os laboratórios de zoologia e de botânica da Universidade de

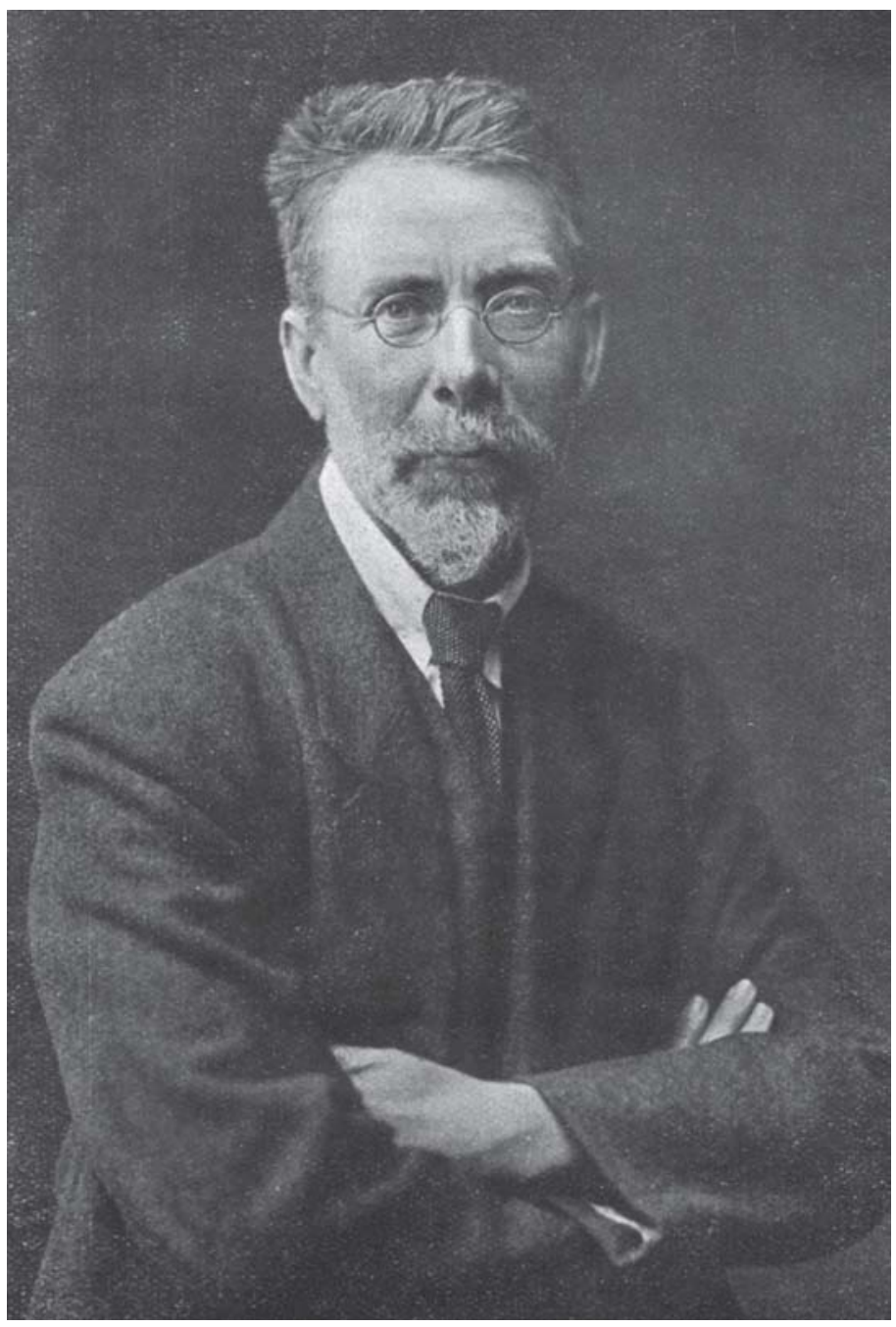

Figura 1 - Jean Massart (Acervo Biblioteca do JBRJ/MMA)
Bruxelas - "as viagens da missão belga aconteceram em várias etapas: Rio de Janeiro; São Paulo; Minas Gerais, Bahia; Pernambuco, Ceará, Pará e Amazonas" (p.5-6).

Nascido em 1865, nas proximidades de Bruxelas, Jean Massart dedicou-se aos estudos das ciências naturais e da medicina, tendo sido professor de botânica em 1895; atuou como pesquisador e professor em outras cidades, como em Paris, no Instituto Pasteur; realizou viagens à Índia e ao continente africano, entre outras; permaneceu na Universidade de Bruxelas entre 1902 e 1906 e dirigiu o Jardim Botânico da mesma cidade.

Em conferência na Société Royale des Sciences Médicales et Naturelles de Bruxelles, Massart resumiu a descrição de sua viagem ao Brasil, ressaltando a acolhida recebida pelas autoridades governamentais e pelos cientistas de diferentes locais e instituições: "Nós desembarcamos no Rio, em 16 de agosto de 1922 depois de três escalas de alguns dias em Recife e na Bahia ... e, seguidamente, recebemos as boas vindas das autoridades administrativas locais ..." (Massart et al., 1930, p.18). 


\section{Os naturalistas belgas e o Jardim Botânico do Rio de Janeiro}

Na cidade do Rio de Janeiro, no Jardim Botânico, Jean Massart e os outros integrantes da 'missão' se fixaram durante cinco semanas: "Um grande laboratório ... e foi colocado à nossa disposição o que nos permitiu aproveitar as maravilhosas coleções do jardim".

Planejadas e dirigidas pelos naturalistas do Jardim Botânico - Pacheco Leão (diretor da instituição), Silveira e Khulmann -, as viagens da 'missão' belga foram realizadas inicialmente com duração de um dia: à Jacarepaguá, à Barra da Tijuca e à Piratininga; às ilhas da baía da Guanabara e à floresta da Tijuca. Os naturalistas foram também a Xerém, com Adolpho Lutz, do Instituto de Manguinhos, e a Deodoro, com Arséne Puttemans, botânico belga ligado ao Ministério da Agricultura do Brasil.

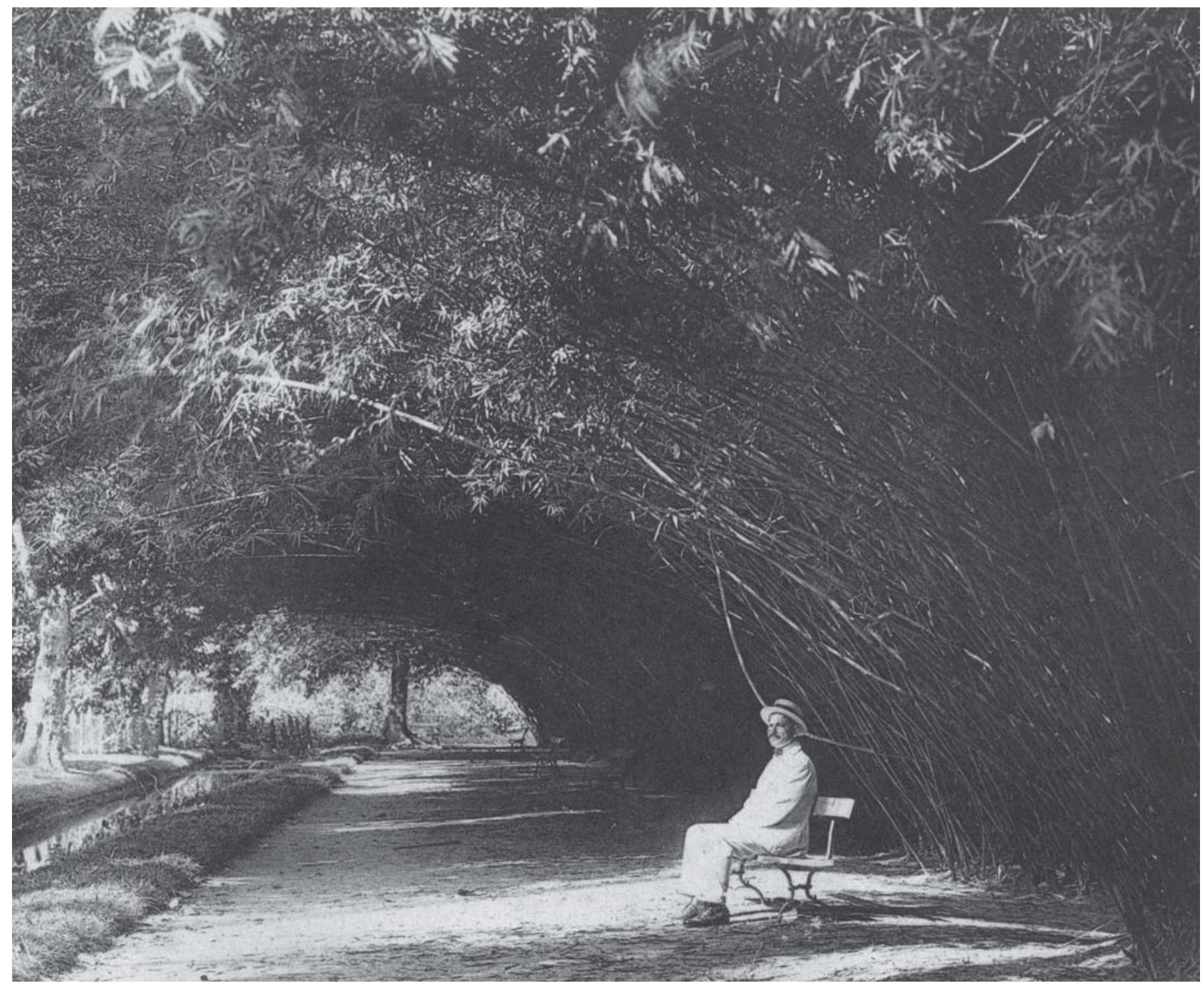

Figura 2 - Aléia de bambus no Arboreto do JBRJ, 1922 (Acervo Biblioteca do JBRJ/MMA) 
Além das viagens de coleta de plantas organizadas pelo Jardim Botânico, os naturalistas realizaram passeios aos mercados do Centro da cidade do Rio de Janeiro, especialmente aos que vendiam artefatos feitos de plantas (Figura 3).

Após as viagens acima mencionadas, os naturalistas belgas e os do Jardim Botânico organizaram viagens a pontos mais distantes do estado, como a Macacu e estação biológica de Itatiaia. Segundo Massart, outra etapa da viagem "muito fértil de ensinamentos" (Massart et al., 1929, p.7) foi a Ouro Branco, em Minas Gerais, onde puderam estudar, a 1.200 metros de altitude, plantas específicas do planalto central do Brasil.

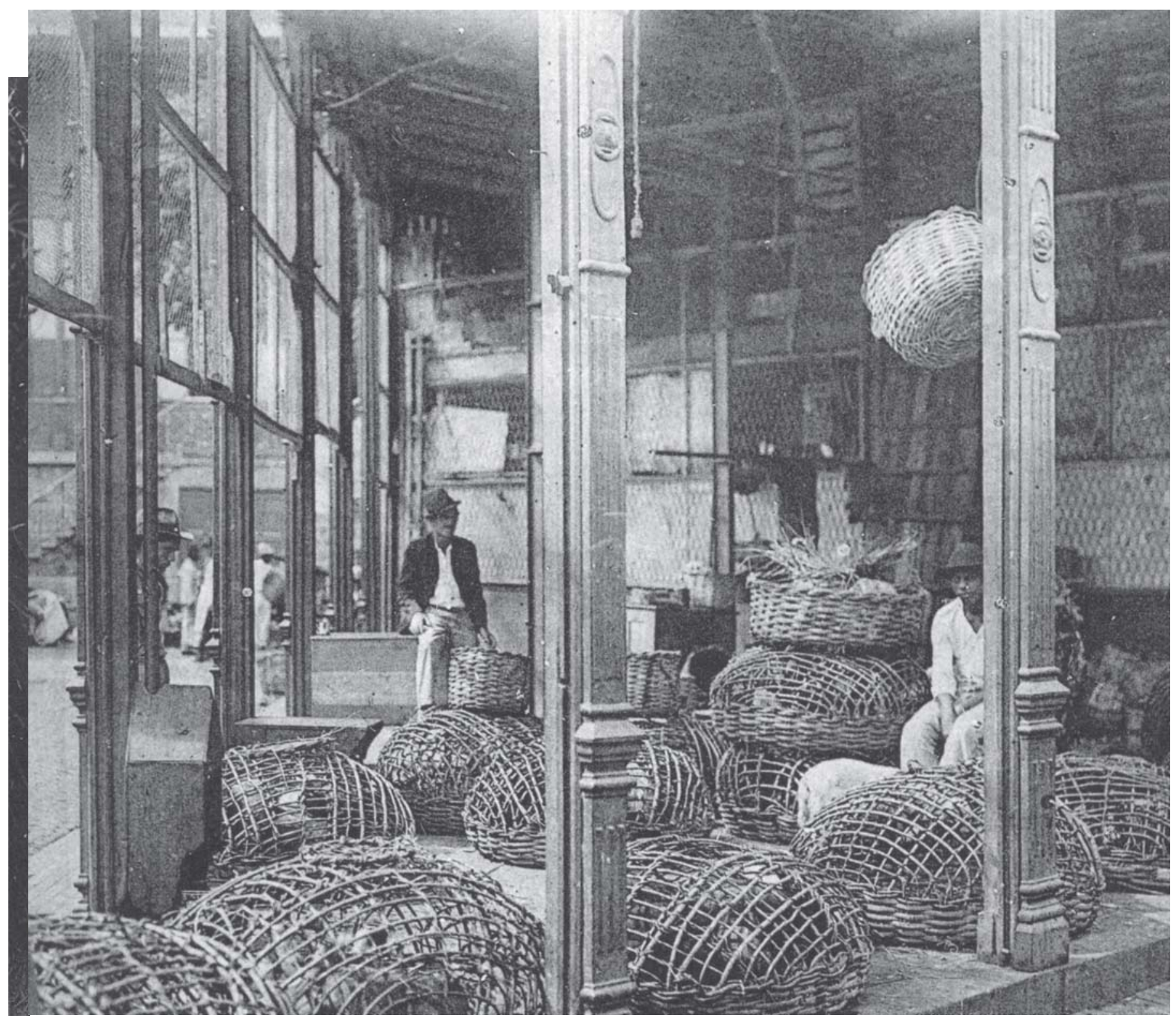

Figura 3 - Mercado de cestos de bambu na cidade do Rio de Janeiro, 1922 (Acervo Biblioteca do JBRJ/MMA) 
Figura 4 - Ouro Branco,

Minas Gerais, 1922 (Acervo

museológico do JBRJ/MMA)

Whato

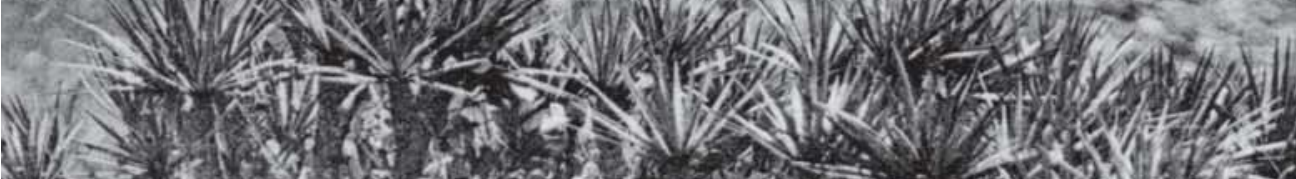

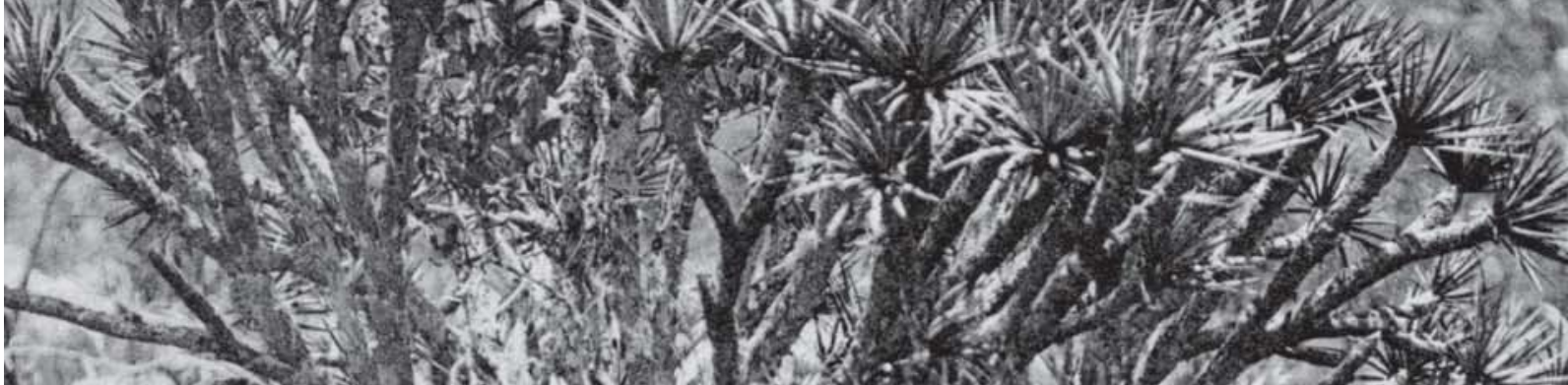

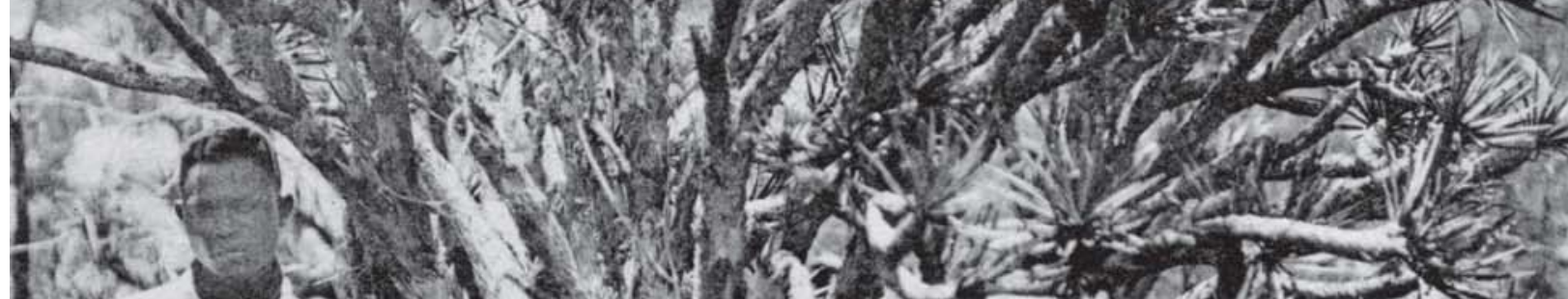

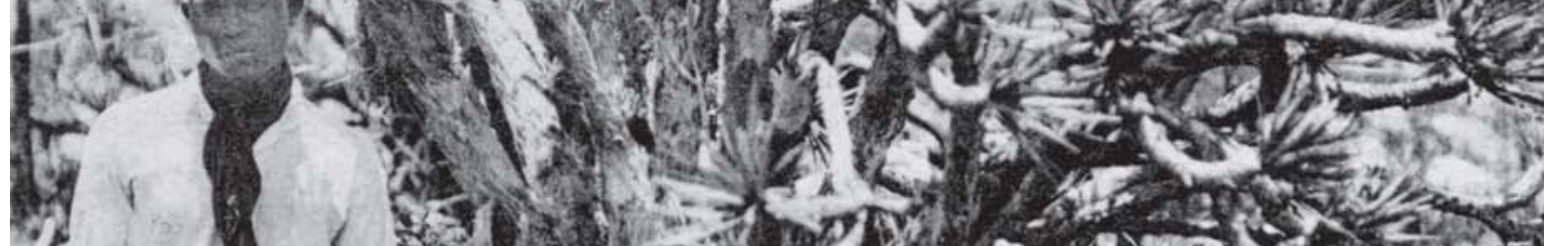

(1)

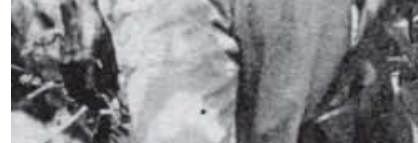

$(1,1)$

(2)

(2)

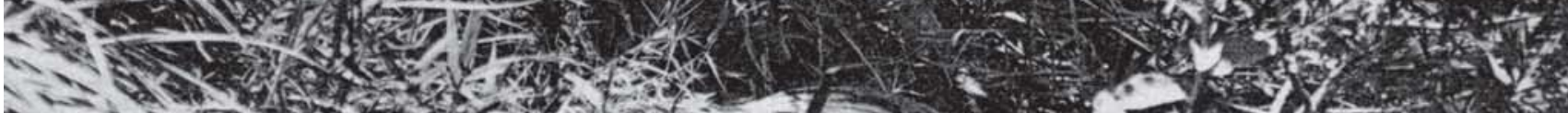

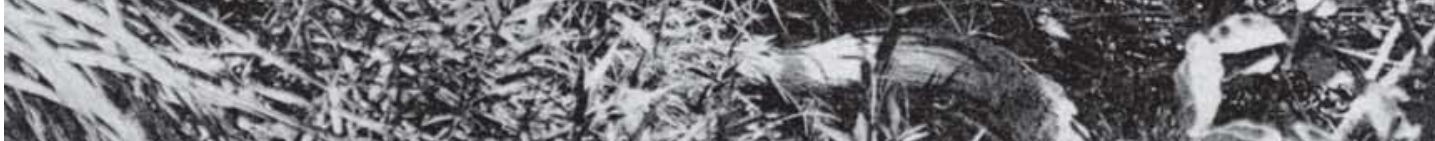

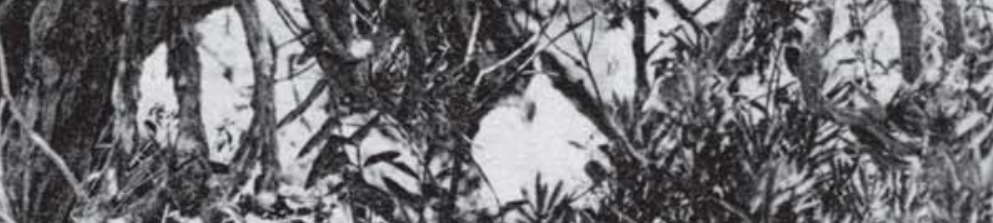

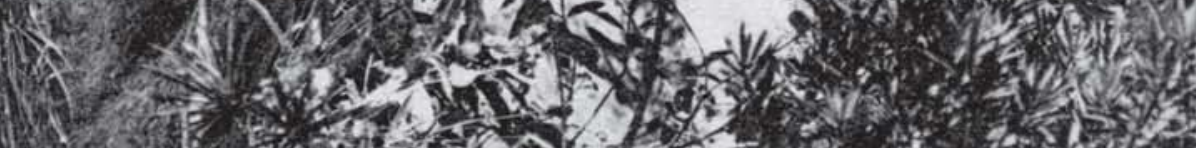


Ao chegar à Bahia, a missão foi acolhida, segundo relato do próprio Massart, com "espírito cordial" e se beneficiou dos caminhos de ferro postos pelas autoridades à disposição dos naturalistas. Um vagão foi transformado em laboratório, o que, conforme os belgas, foi fundamental para as pesquisas. Além disso, os naturalistas ressaltaram que o trem viabilizou o contato com regiões quase inacessíveis e praticamente desérticas.

Uma observação recorrente nos escritos dos membros da 'missão' refere-se à variação do clima e aos efeitos nas paisagens em diferentes locais: "Perto de Joazeiro e perto de Itumirim, nós visitamos regiões secas onde não chovia há um ano: florestas dominadas por cactus ..." (Massart et al., 1929, p.86).

Em janeiro de 1923, Jean Massart partiu da Bahia rumo à Europa. Seus companheiros seguiram viagem em direção ao Norte, com o objetivo de estudar a vegetação e a fauna do baixo-Amazonas.

A bordo de um navio do Lloyd Brasileiro que fazia escala em Pernambuco, Fortaleza (Ceará) e São Luís (Maranhão), os integrantes da 'missão', já sem Jean Massart, desembarcaram em Belém (Pará), onde foram recebidos por autoridades locais, o cônsul da França e o da Bélgica e pelo cientista Adolphe Duke, chefe de seção do JBRJ que estava em missão exploratória na floresta amazônica.

Os resultados dos estudos dos especialistas compõem as distintas partes da obra editada sobre a 'missão'. Manaus, e Óbidos (Figura 7), Santarém, Monte Alegre, Porto de Moz, entre outros locais, receberam a visita dos naturalistas belgas.

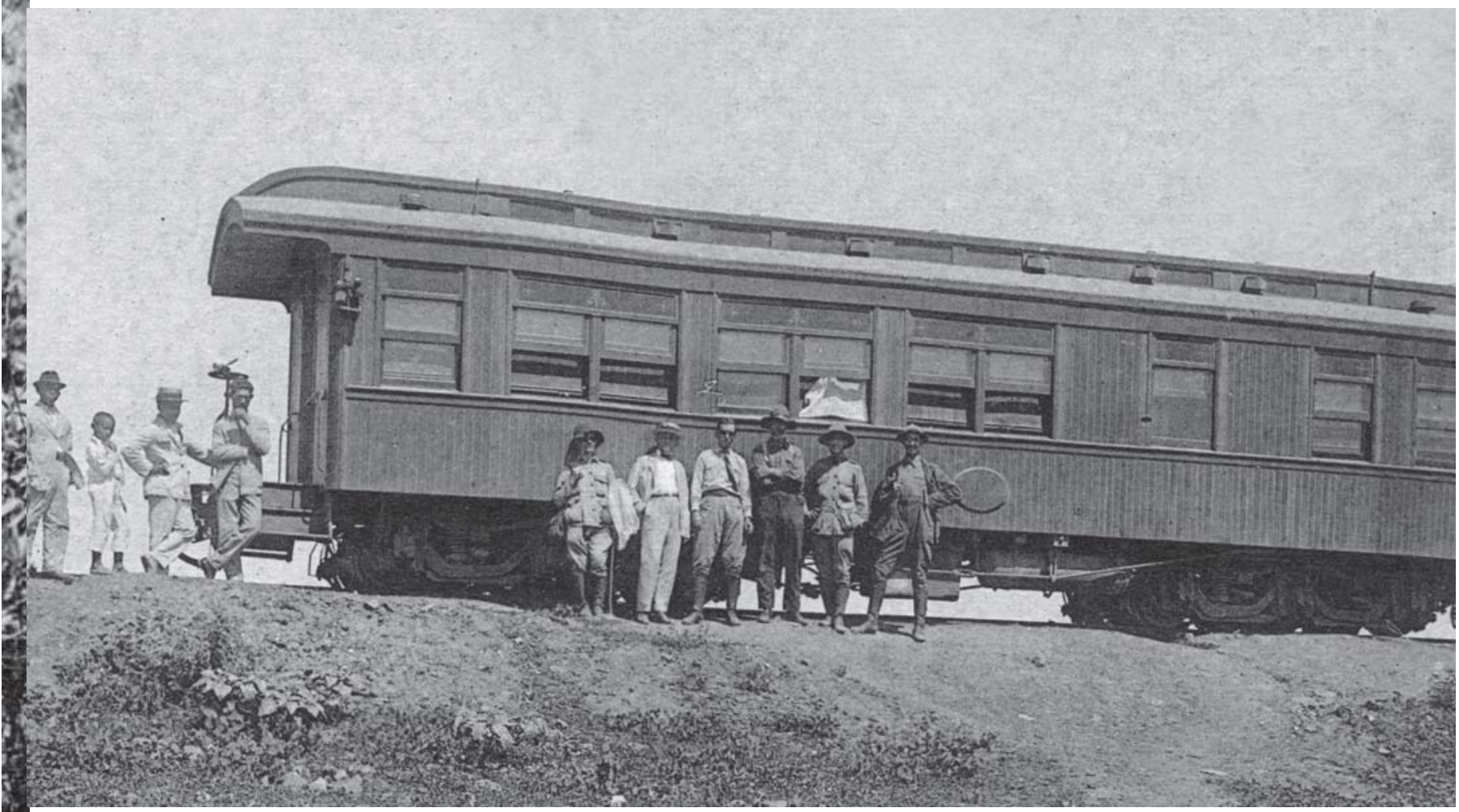

Figura 5 - Vagão-leito que serviu de hotel para os integrantes da 'missão', 1922 (Acervo da Biblioteca do JBRJ/MMA) 
Figura 7 - Integrantes da 'missão' na Caatinga de Itumirim, 1922

(Acervo da Biblioteca do

JBRJ/MMA)

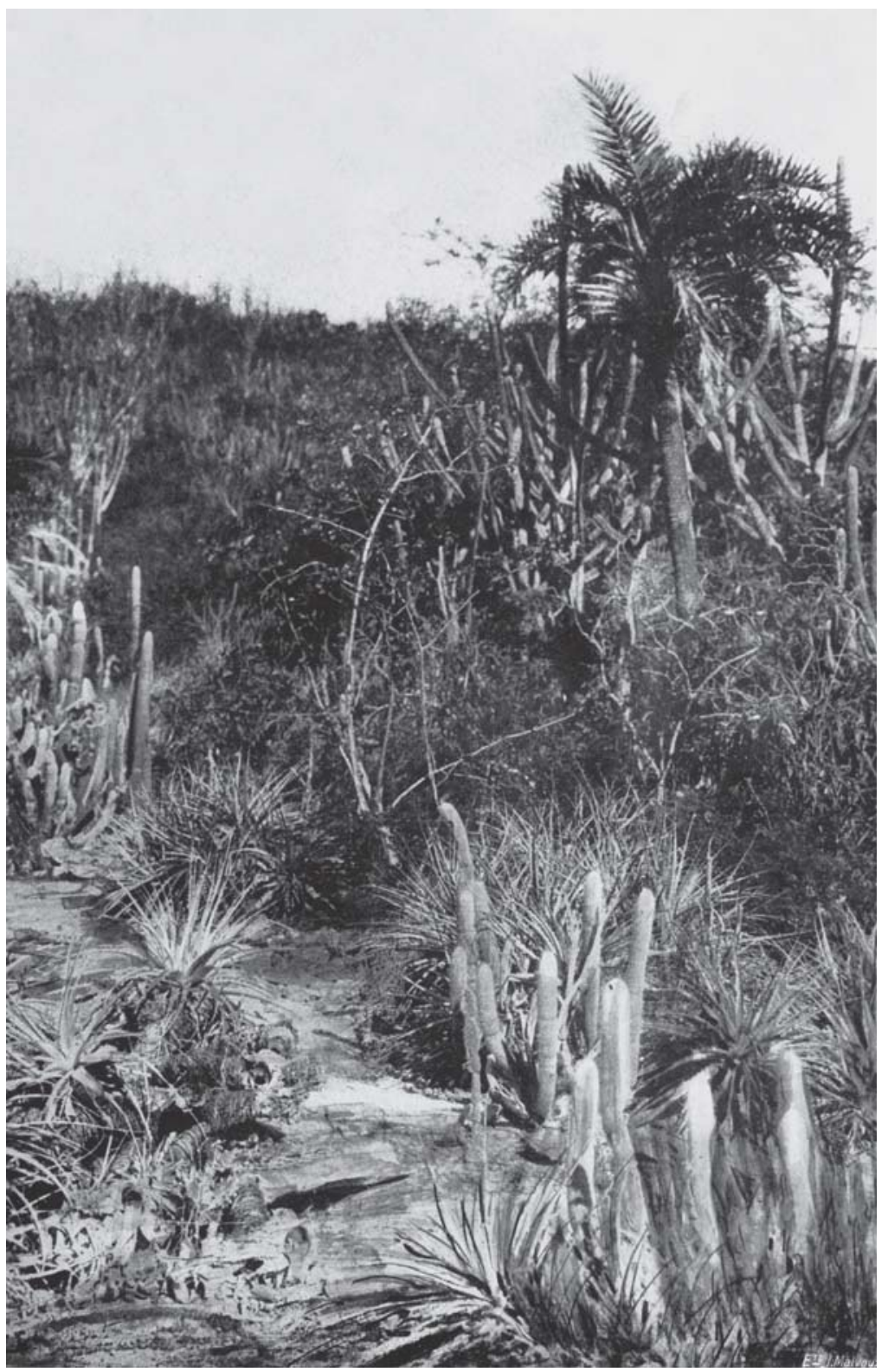

Figura 6 - Itumirim. Foto de Jean Massart, 1922 (Acervo da Biblioteca do JBRJ/MMA)

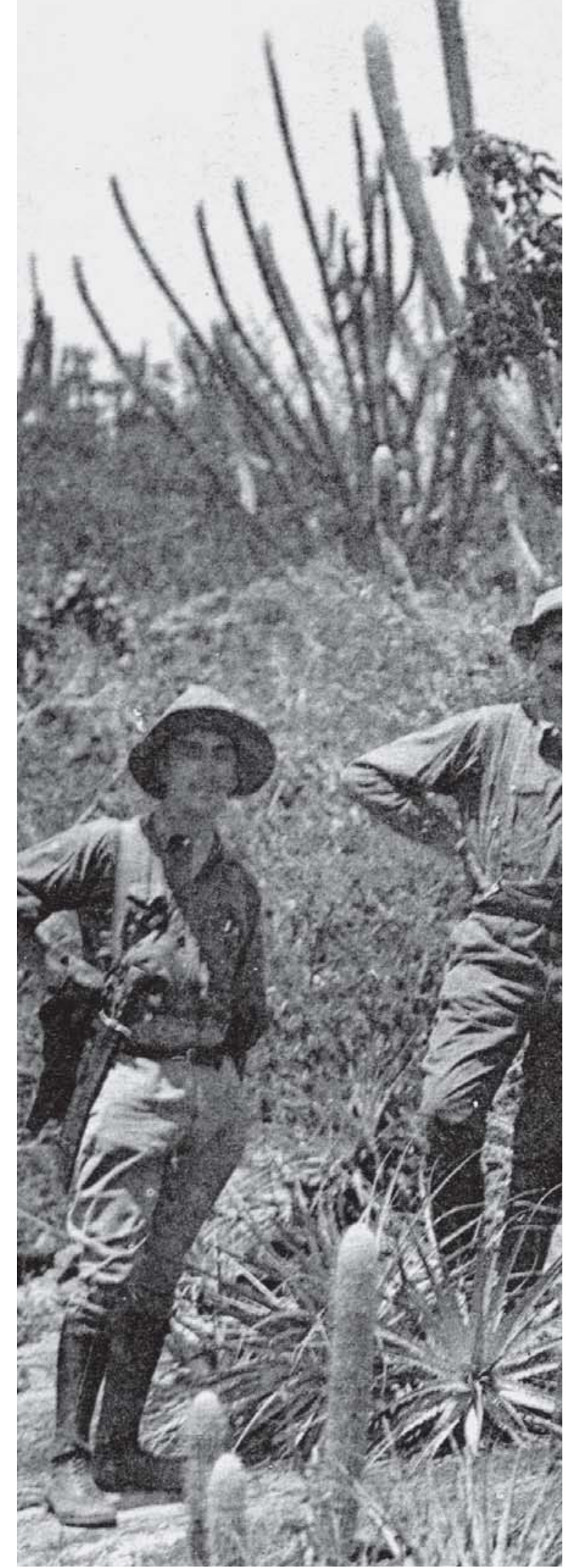




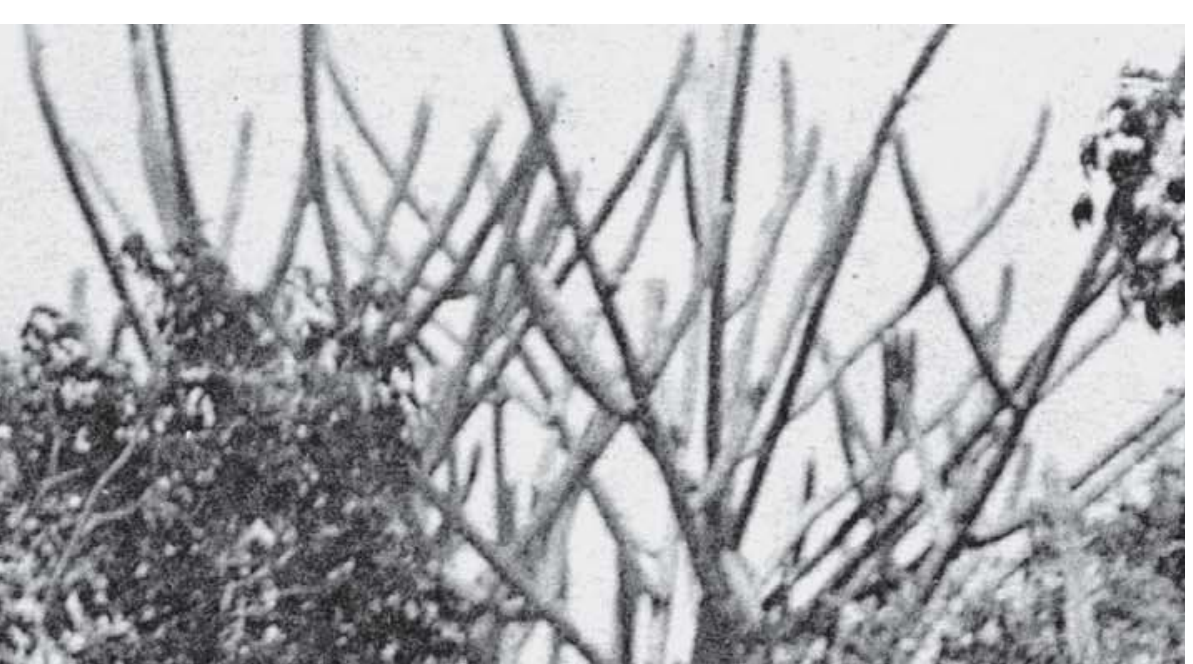

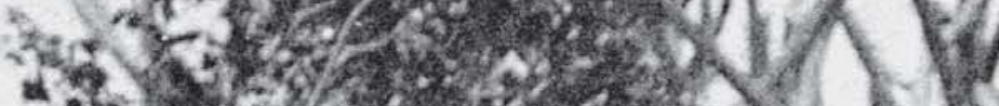
$-205: 0$ -

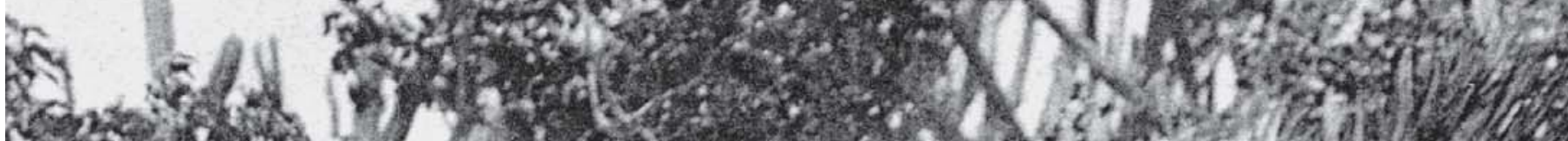
1. 5 . To 0. 
Bouillenne, no capítulo "Un voyage botanique..." (Massart et al., 1929), introduz o que chamou de extrato do jornal de viagem do autor descrevendo o que via: "a vida a bordo do navio Ceará continua agradável, repousante, após duas duras etapas que nós terminamos no sertão (interior) do Estado da Bahia, onde nós visitamos as caatingas: desertos, os campos e as savanas" (p.16). Bouillenne enfatiza as colaborações dos cientistas que os receberam em diferentes cidades, como o já mencionado Adolphe Duke.

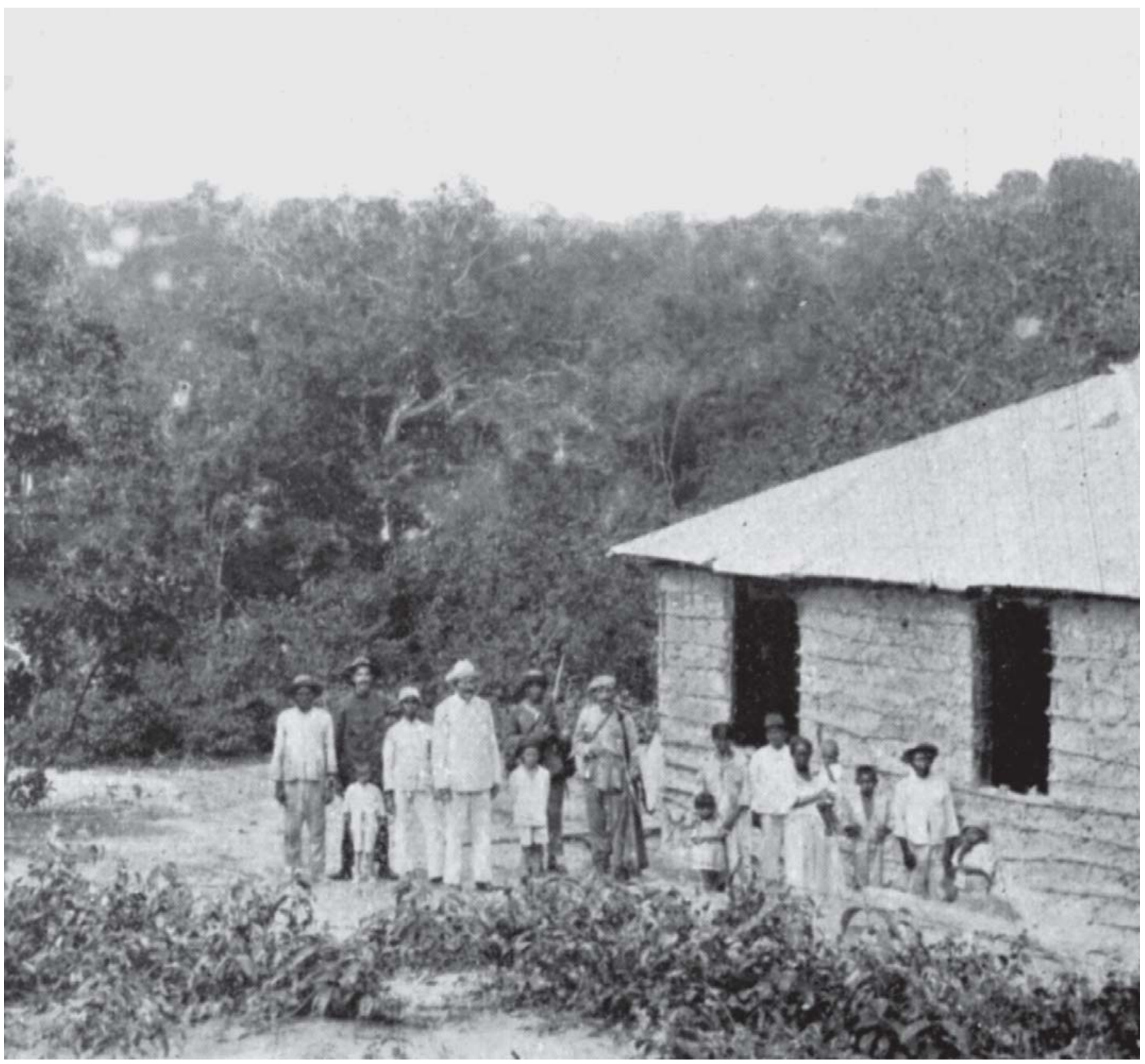

Figura 8 - Trabalhadores rurais em Óbidos, no Pará, 1923 (Acervo Biblioteca do JBRJ/MMA) 


\title{
A obra
}

O resultado das viagens dos naturalistas belgas ao Brasil foi publicado sob as formas de diário, relatório e artigos escritos pelos membros da 'missão'. Tais registros contêm informações sobre lugares e gentes com os quais os naturalistas se depararam no percurso da viagem. Foram reunidos em dois volumes sob o título Une mission biológique belge au Brésil. (Août 1922 - Mai 1923).

\section{UNE}

\section{MISSION BIOLOGIQUE BELGE}

\section{AU BRÉSIL}

\author{
(Août 1922 - Mai 1923)
}

PAR

\author{
† Jean MASSART \\ Professeur de Botanique à l'Université de Bruxelles; \\ Directeur de la Mission.
}

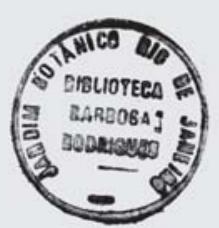

ET

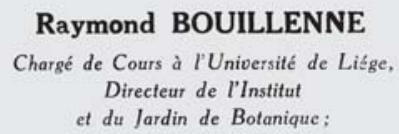

Paul BRIEN

Chargé de Cours à l'Université de Bruxelles;

Membres de la Mission.

\section{Paul LEDOUX \\ Administrateur \\ de l'Institut de Botanique Léo Errera de l'Université de Bruxelles;}

\section{Albert NAVEZ}

Associated-Professor à Harvard University Boston (U.S.A.);

TOME $I^{\text {er }}$

Ouvrage publié avec l'aide de la Fondation Universitaire de Belgique.

BRUXELLES

IMPRIMERIE MEDICALE ET SCIENTIFIQUE (S. A.)

34 , Rue Botanique

$1 \overline{929}$

Figura 9 Frontispício da obra que relata a viagem da 'missão' belga ao Brasil em 1922 e 1923 (Acervo Biblioteca do JBRJ/MMA) 
Lançada após a morte de Jean Massart, seu inspirador, a obra é composta de anotações sobre botânica, zoologia, costumes e comentários pessoais que constituíram um projeto apoiado pelo meio acadêmico, bem como por autoridades governamentais da Bélgica. Segundo o botânico Marchal, prefaciador de uma das edições, o material decorrente dessa viagem era extremamente importante para o estudo da biogeografia e da etologia botânica do Brasil.

"Impressões de viagens" abrem os dois volumes e, além das descrições sobre o que viram e coletaram para seus estudos, os integrantes da missão fotografaram, eles próprios, esse material, uma vez que não havia fotógrafo acompanhando o grupo. Segundo o botânico Bouillenne, autor da maioria das fotografias da 'missão' belga, centenas de clichês fotográficos foram produzidos pelos integrantes da missão. Não se sabe ao certo o número total de reproduções, mas uma observação na obra indica que as perdas foram consideráveis: "todo mundo compreende que a observação, o recolhimento e a fotografia são penosas nas regiões equatoriais ... sobre a gelatina dos clichês o calor úmido provoca em curto prazo o desenvolvimento de abundante mofo" (Massart et al., 1930, p.8). De fato, tratados somente no retorno à Bélgica, muitos clichês da Amazônia não resistiram (Ferrari, 1993). Para o botânico Marchal, tratava-se de uma preciosa documentação que permitiria escrever uma 'relação científica' minuciosa da viagem ao Brasil.

É possível observar, na obra, a complementaridade entre textos e imagens, especialmente quando dizem respeito a informações sobre os habitantes das regiões percorridas e seus costumes. Revelam-se ao leitor informações preciosas sobre os diferentes modos de vida dos habitantes das regiões visitadas.

Entre os registros da viagem, a Amazônia ganhou destaque, bem como "a atividade científica de excelência do Instituto Oswaldo Cruz - a campanha de salubridade pública em postos avançados de profilaxia rural" (Massart et al., 1929, p.11).

O Museu Goeldi, em Belém, também referido, foi criticado pelos naturalistas quanto ao estado de conservação das coleções, que teriam sido negligenciadas devido à crise financeira por que passaram os estados do Pará e do Amazonas, com o declínio da produção e da comercialização da borracha. Mas os biólogos belgas elogiam a atuação do naturalista Adolphe Duke no Museu Goeldi, sobretudo quanto à publicação de estudos de botânica sobre a região: "o botânico Huber e seu sucessor Duke se associaram na audácia de exploração e à publicação ininterrupta e em série num país aonde [sic] o trabalho contínuo é dos mais penosos. Ao mesmo tempo seus artigos constituem hoje a fonte principal de nossa documentação botânica" (Massart et al., 1929, p.93).

Em maio de 1923, a missão retornou à Bélgica, com uma escala nos Açores.

\section{Conclusão}

Algumas impressões de viagem se atualizam ao longo destes dois séculos e, por vezes, são recuperadas por autores na atualidade. Impressões que permanecem nos livros, nas imagens e nos debates políticos. Trata-se de uma série de construções históricas que partiam de 'preconcepções' sobre o Brasil e que podem se traduzir em objeto de análise para o historiador. Os exemplos são muitos, e os 'intérpretes do Brasil' também. O fato é que 


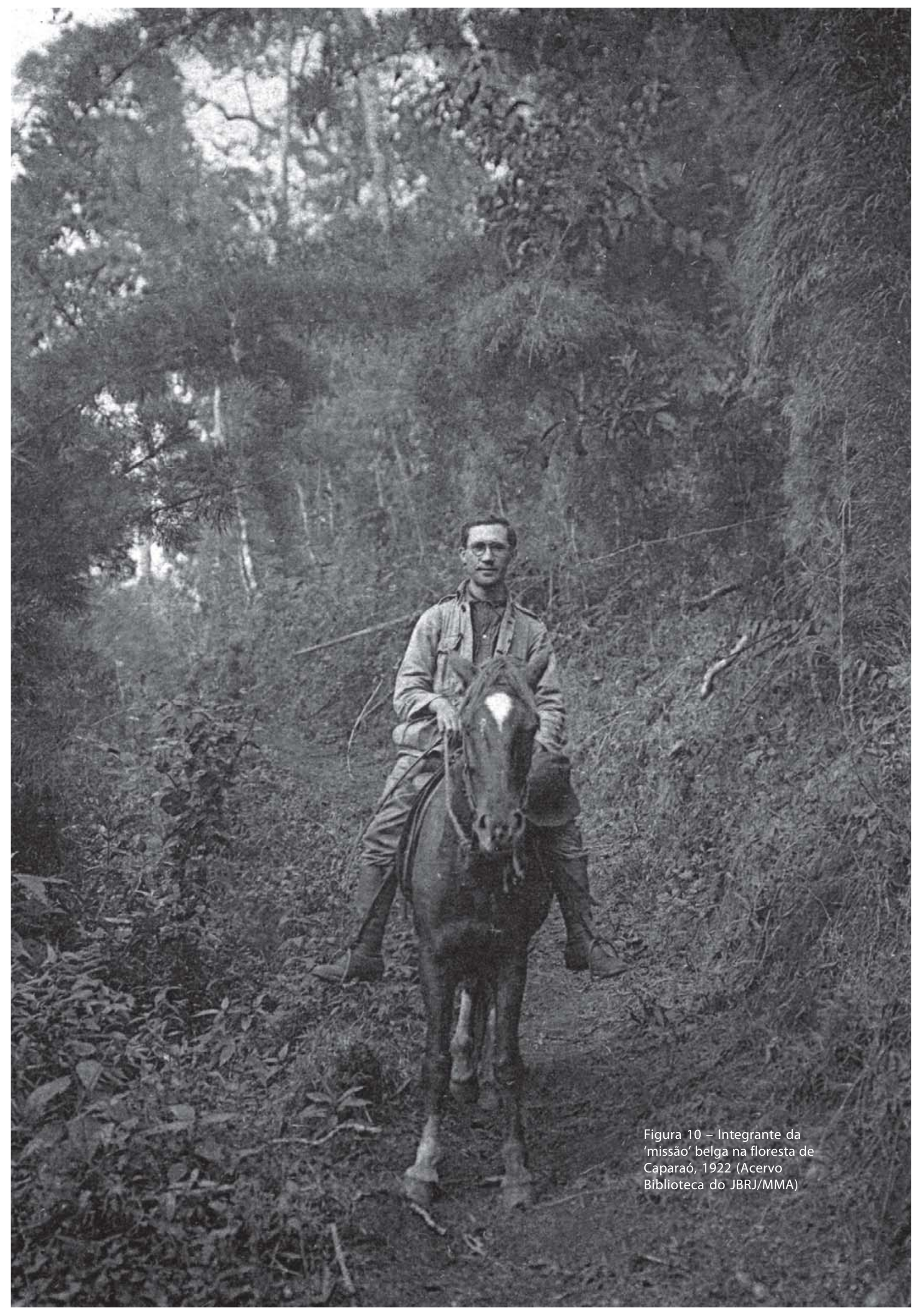


paisagens são definidas e redefinidas a partir de olhares diferenciados, com objetivos distintos.

O material recolhido nas viagens - na maioria das vezes depositado nos herbários de jardins botânicos ou integrado a acervos de museus europeus - traz consigo o registro de quem os recolheu e os inventariou. Utilizado na comunicação entre cientistas e instituições, passa a ter outros significados quando é alocado em novas paragens, compreendido em outros tempos.

Não resta dúvida de que a Amazônia tem sido objeto de interesse de estudiosos e escritores, podendo-se, inclusive, afirmar que sempre esteve e permanece na 'ordem do dia'. Disputada historicamente por grupos que pretendiam obter privilégios ou manter os que já detinham, a Amazônia aparece também nos discursos dos políticos e ambientalistas, e neles encontramos elementos para pensar como os que passaram pela região ou a tiveram ou têm como objeto (e projeto) construíram e constroem imagens sobre ela e sobre si próprios.

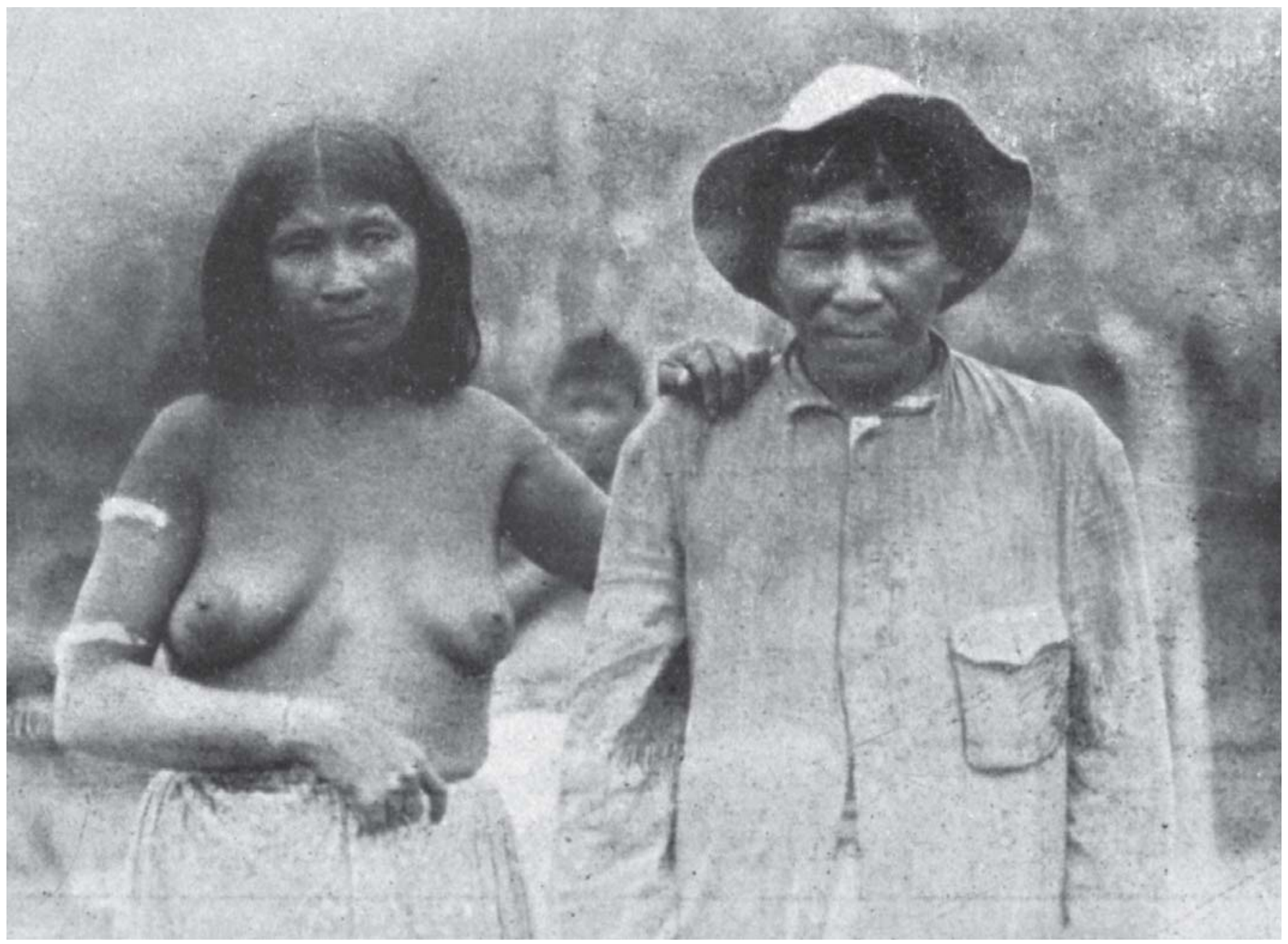

Figura 11 - Casal de 'Tapuios', 1922 (Acervo Biblioteca do JBRJ/MMA) 
Nos registros da 'missão' belga, do início do século XX, uma descrição sobre a população ressalta esse aspecto: "Pergunta-se como pode ser a vida do homem numa tal região? Suas casas estabelecidas sobre pilotis mal fixados na lama das praias são simples tábuas de troncos de palmeiras amarradas por cipós. Elas são cercadas pelos miasmas ... . A vida ali é quase impossível. E, no entanto, uma raça de índios ali subsiste ..." (Massart et al., 1929, p.92).

Na mesma publicação, o autor reforça suas conclusões ao registrar em nota uma obra do final do século XIX e, portanto, anterior à viagem ao Brasil, que o auxiliou a interpretar aquelas fotografias e descrições dos habitantes locais: "eles não cultivam nada ... a nota dominante do seu caráter é a falta absoluta de energia e de ação. Eles vivem dominados por uma espécie de fatalismo inconsciente, atribuído às características climáticas da região amazônica."

Sendo assim, podemos afirmar que buscar nas construções de sentido elementos que nos possibilitem lançar mão de outras possibilidades de reflexão sobre as fotografias e suas mediações pode ser um caminho interessante para o estudo do 'lugar' das imagens na história das ciências e, em particular, na história da fotografia.

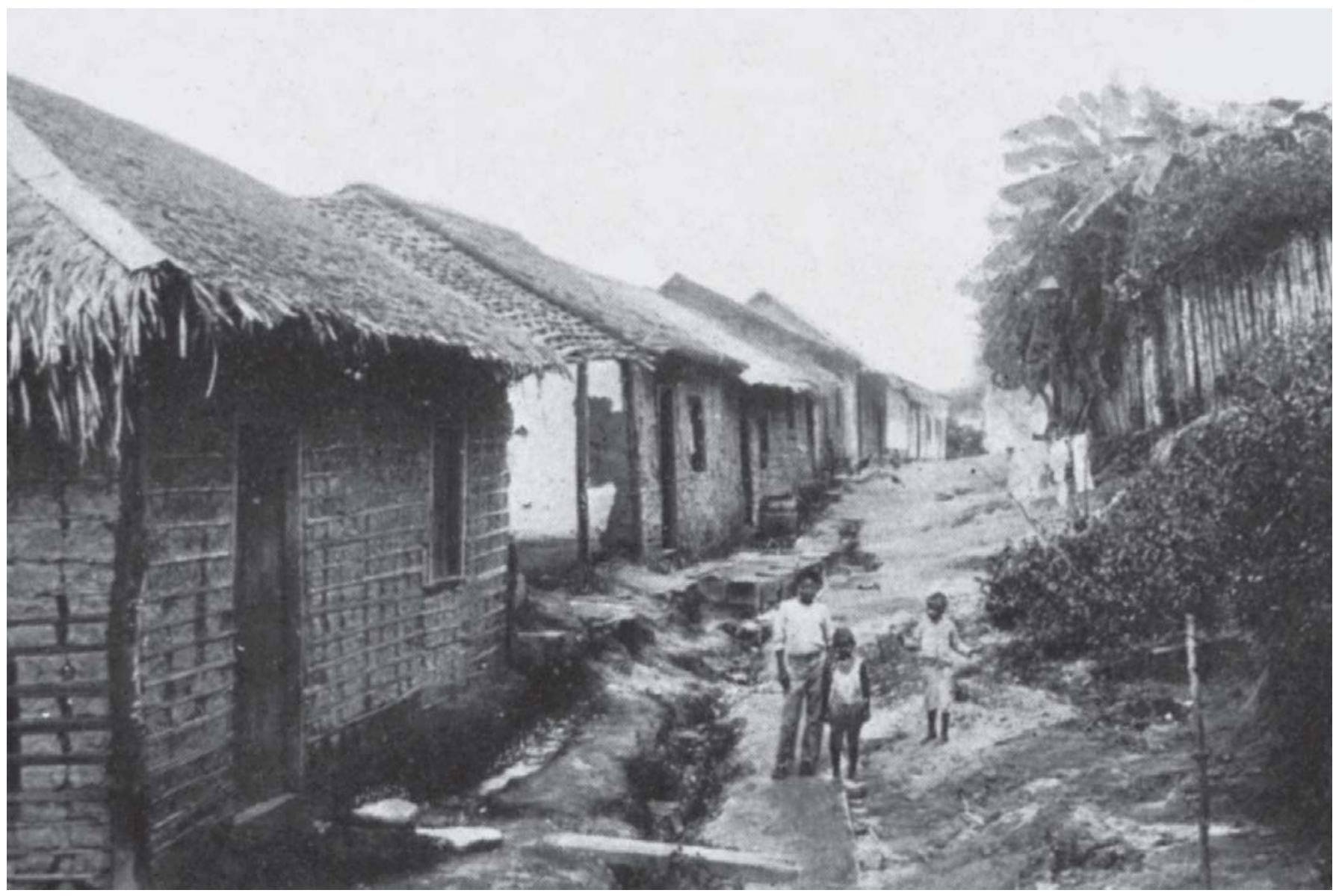

Figura 12: Crianças na rua de uma vila na Amazônia, 1922 (Acervo Biblioteca do JBRJ/MMA) 


\section{AGRADECIMENTOS}

Agradeço a Pierre Meerts, diretor do Jardin Botanique Expérimental Jean Massart, as informações sobre o material resultante da missão belga, à bióloga Carmen Machado e à Rosana Simões Medeiros, bibliotecária do Jardim Botânico do Rio de Janeiro.

\section{REFERÊNCIAS}

\section{BOLETIM...}

Boletim do Museu Botânico Khulman. Rio de Janeiro, ano 7, n.1. 1984.

FERRARI, Roberto A.

Los inicios de la fotografia científica y técnica en la Argentina, 1864-1900. In: Congreso de Historia de la Fotografia, 2, 1993, Buenos Aires. 2do Congreso... Buenos aires: Circulo Médico de Vicente Lopez. p.159-165. 1993.

GUIMARÃES NETO, Regina Beatriz. Território de ocupação recente na Amazônia., Iin: Chaloub, Sidney; Neves, Margarida de Souza; Pereira, Leonardo Affonso de Miranda. História em cousas miúdas. Campinas: Unicamp Editora. p.519-546. 2005.

LÉVI-STRAUSS, Claude.

Saudades do Brasil. São Paulo: Companhia das Letras. 1994.
LIMA, Nísia Trindade.

Missões civilizatórias da República e interpretação do Brasil. História Ciências, Saúde - Manguinhos, Rio de Janeiro, v.5, supl., p.163-193. jul. 1998.

MASSART, Jean et al. Une mission biológique belge au Brésil. 1922-1923. Bruxelas: Imprimerie Medicale et Scientifique. 1930.

MASSART, Jean et al.

Une mission biologique belge au Brésil (aôut 1922mai 1923). Bruxelles: Imprimerie Medicale et Scientifique. 1929.

MORAES, Antonio Carlos Robert Moraes. O sertão: um 'outro' geográfico. Terra Brasilis, São Paulo, n.4-5, p.11-23. 2002-2003.

OLIVEIRA, Ana Rosa.

Tantas vezes paisagem. Rio de Janeiro: FAPERJ. 2007.

\section{$\rightarrow \rightarrow \rightarrow<<$}

